\title{
Retrospective study on the effectiveness of a prevention strategy in a dental hospital during the COVID-19 pandemic
}

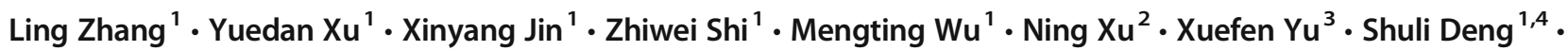 \\ Kai Zhang ${ }^{5}$. Liefen Zhang ${ }^{2}$. Matthias Hannig ${ }^{6}$. Qianming Chen ${ }^{1,2}$. Baiping Fu ${ }^{1,2,3}$ (D)
}

Received: 12 May 2020 / Accepted: 12 March 2021 / Published online: 18 March 2021

(C) The Author(s), under exclusive licence to Springer-Verlag GmbH Germany, part of Springer Nature 2021

\begin{abstract}
Objectives To evaluate the effectiveness of a prevention strategy against the spread of SARS-CoV-2 infection among dental hospital staff over a 3-month period.

Materials and methods The effectiveness of the prevention strategy, which adopted healthcare staff protective measures, including patient triage and correct usage of personal preventive equipment, was evaluated by SARS-CoV-2 detection and serological testing. Patients who visited the Affiliated Stomatology Hospital, Zhejiang University School of Medicine, Hangzhou, China, between January 31 and March 1 (lockdown period) and March 2 and April 27 (reopening period) in 2020 and in the same period in 2019 were included in the study. Patients' diagnosis, age, gender, and several undergoing aerosolgenerating procedures during the study period were collected from the hospital's database. Corresponding data were compared year-on-year (2020-on-2019). A total of 757 hospital staff underwent SARS-CoV-2 detection and serological testing on April 28-29, 2020.

Results During the lockdown and reopening period in 2020, the number of hospital visits was dramatically decreased to about $6 \%$ and $58 \%$, respectively, compared with the same period in 2019. However, emergency visits were increased 16- and 6.4-fold. A total of at least 6654 patients (13.58\%) underwent aerosol-generating procedures during the study period in the year 2020. All hospital staff were negative according to SARS-CoV-2 detection and serological testing (IgG, IgM) data.

Conclusion During the study period in 2020, the total number of hospital visits dramatically reduced but emergency visits significantly increased. The prevention strategy implemented successfully prevented SARS-CoV-2 infection spread among healthcare workers in a dental hospital.

Clinical relevance The prevention strategy indicated patient triage and how to adopt preventive measures for controlling SARSCoV-2 spread among healthcare workers. These data can be used as a reference for other sectors suffering from the COVID-19 pandemic.
\end{abstract}

Keywords COVID-19 $\cdot$ SARS-CoV-2 $\cdot$ Dental healthcare $\cdot$ Prevention strategy $\cdot$ Aerosols

Ling Zhang and Yuedan Xu contributed equally to this work.

Xuefen Yu

yuxf@zju.edu.cn

Baiping Fu

fbp@zju.edu.cn

1 Department of Prosthodontics, The Affiliated Hospital of Stomatology, School of Stomatology, Zhejiang University School of Medicine and Key Laboratory of Oral Biomedical Research of Zhejiang Province, Zhejiang 310006, Hangzhou, China

2 Department of Medical Administration, The Affiliated Hospital of Stomatology, School of Stomatology, Zhejiang University School of Medicine, Yan'an Road 395, Zhejiang 310006, Hangzhou, China
3 Department of Control and Prevention of Nosocomial Infection, The Affiliated Hospital of Stomatology, School of Stomatology, Zhejiang University School of Medicine, Yan'an Road 395,

Zhejiang 310006, Hangzhou, China

4 Department of Conservative and Operative Dentistry, The Affiliated Hospital of Stomatology, School of Stomatology, Zhejiang University School of Medicine, Yan'an Road 395, Zhejiang 310006, Hangzhou, China

5 Department of Dental Emergency, The Affiliated Hospital of Stomatology, School of Stomatology, Zhejiang University School of Medicine, Yan'an Road 395, Zhejiang 310006, Hangzhou, China

6 Clinic of Operative Dentistry, Periodontology and Preventive Dentistry, Saarland University, Homburg, Saarland, Germany 


\section{Introduction}

The epidemic outbreak of coronavirus disease 2019 (COVID19), originating in Wuhan, China, in December 2019, has rapidly evolved into a public emergency of international concerns and finally became a pandemic [1]. At present, humanto-human transmission of SARS-CoV-2 via close contacts has been confirmed, including direct transmission and contact transmission [2]. The direct transmission mode indicates that SARS-CoV-2 infection is attributable to transmission via droplet inhalation, in which droplets are produced by cough and sneeze [3]. Moreover, the contact transmission mode indicates that individuals can be infected by touching contaminated surfaces and involuntarily touching their own mouth, nose, or eyes [4, 5]. In addition, SARS-CoV-2 transmission has also been confirmed to occur via aerosols or the fecal-oral route $[3,6,7]$.

Dentists and nurses face a high risk of infection since they are exposed to saliva, blood, droplets, and aerosols that are generated by high-speed handpiece and ultrasonic instruments that are routinely used in the dental clinic [8]. Except for emergency cases, routine dental clinic work was suspended in cities and countries in lockdown to reduce SARS-CoV-2 transmission, while non-lockdown cities and countries still provided routine dental procedures for regular patients [9, 10]. Asymptomatic COVID-19 cases have also been reported [11]. This has significantly increased the great risk of SARSCoV-2 transmission among dental healthcare personnel [12, 13]. Hence, the public demand for dental care has been a challenge during the COVID-19 pandemic [9].

To control the COVID-19 pandemic, many countries have implemented social distancing, a cough etiquette, international travel restrictions, and quarantine of suspected cases, and international travelers coming from severe pandemic countries and territories [14]. Currently, several vaccine candidates are in phase 3 clinical trials, and their effectiveness is being evaluated [15]. Patients with mild COVID-19 symptoms, who are asymptomatic or pre-symptomatic, might seek dental treatment; therefore, preventive measures should be strictly implemented in dental hospitals $[16,17]$. Healthcare staff protective measures are important during the COVID-19 pandemic [3].

Due to the COVID-19 epidemic outbreak in Zhejiang province, China, routine dental procedures were suspended from the end of January 2020 to March 1, 2020. Most dental clinics and hospitals in Hangzhou, China, were closed during the lockdown period from January 29 to March 1, 2020, and only emergency cases were treated. As of March 2, 2020, our province has gradually reopened. To date, a global consensus of an effective prevention strategy for preventing COVID-19 spread in dental hospitals and clinics has not been reached $[8,14]$. We proposed a prevention strategy for controlling the COVID-19 spread in dental hospitals and clinics. The dental quality control center of the Zhejiang province popularized the prevention strategy in dental clinics and dental hospitals in the Zhejiang province. For qualitative detection of SARS-CoV-2, the World Health Organization has recommended reverse transcription polymerase chain reaction (RT-qPCR) testing on respiratory tract specimens [18]. Moreover, serological testing for specific anti-SARS-CoV-2 IgG and/or IgM has been recognized as important in assisting the diagnosis of COVID-19 [19].

The effectiveness of a standardized prevention strategy for preventing the COVID-19 spread should be sufficiently investigated [10]. Therefore, a retrospective study was performed to evaluate the effectiveness and significance of the prevention strategy for controlling the spread of SARS-CoV-2 among healthcare workers in a dental hospital over a 3 -month period. The prevention strategy was adopted and strictly implemented by the Affiliated Stomatology Hospital, Zhejiang University School of Medicine (Hangzhou, China).

\section{Materials and methods}

\section{Prevention strategy for controlling the spread of COVID-19}

To prevent the spread of COVID-19 during dental procedures, a novel prevention strategy for halting the spread of COVID19 among dental hospital staff was proposed. Healthcare staff protective measures before and during dental procedures are summarized in Table 1.

Patient triage was mainly performed according to temperature measurements and a questionnaire about the epidemiological history and cause of fever. This is detailed in Fig. 1.

\section{Data source}

All patients who visited the Affiliated Hospital of Stomatology, Zhejiang University School of Medicine (Hangzhou, China) between 31 January and 27 April 2020, as well as patients who visited the hospital in the corresponding period in 2019, were included in this retrospective study. According to COVID-19 epidemic spread in Zhejiang province, China, the epidemic spread period was divided into the lockdown and the reopening period. The lockdown period was from January 31, 2020, to March 1, 2020, during which only emergency patients were treated. The reopening period was from March 2 to April 27, 2020, when the COVID-19 outbreak had been controlled, during which regular dental procedures were resumed except for dental implant placement surgery, ultrasonic scaling, and tooth preparations for crown and bridge restorative procedures. Patients' data were obtained from the hospital's database and analyzed based on patients' gender, age, and diagnosis. Patients' diagnosis and 


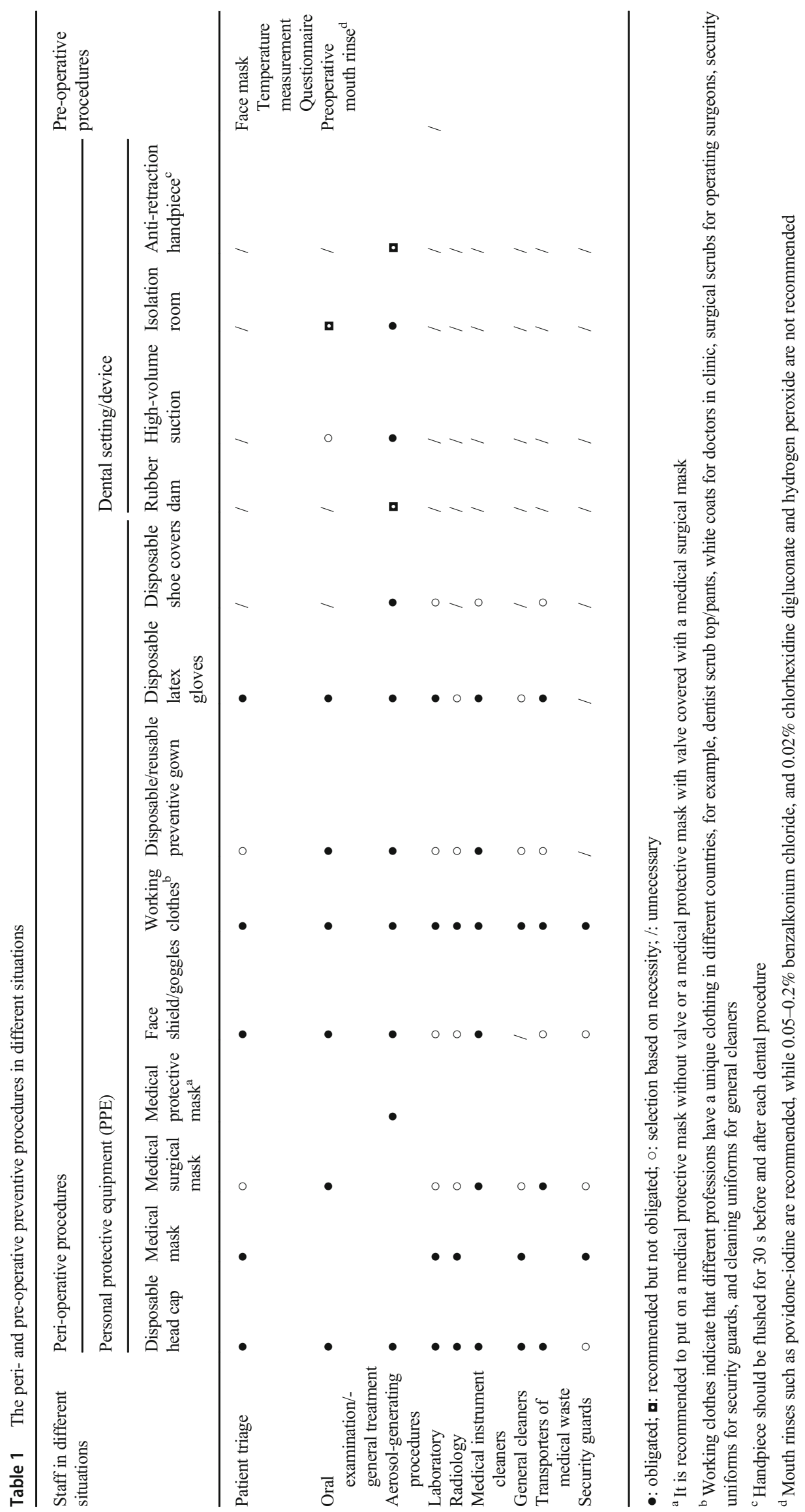


Fig. 1 Illustration of patient triage in the hospital. Epidemiological history includes (within the past 14 days) travel to/or resident in severe COVID-19 epidemic countries and territories; close contact with individuals coming from severe COVID-19 epidemic countries and territories; and close contact with patients with confirmed COVID-19 infection/ suspected COVID-19 cases

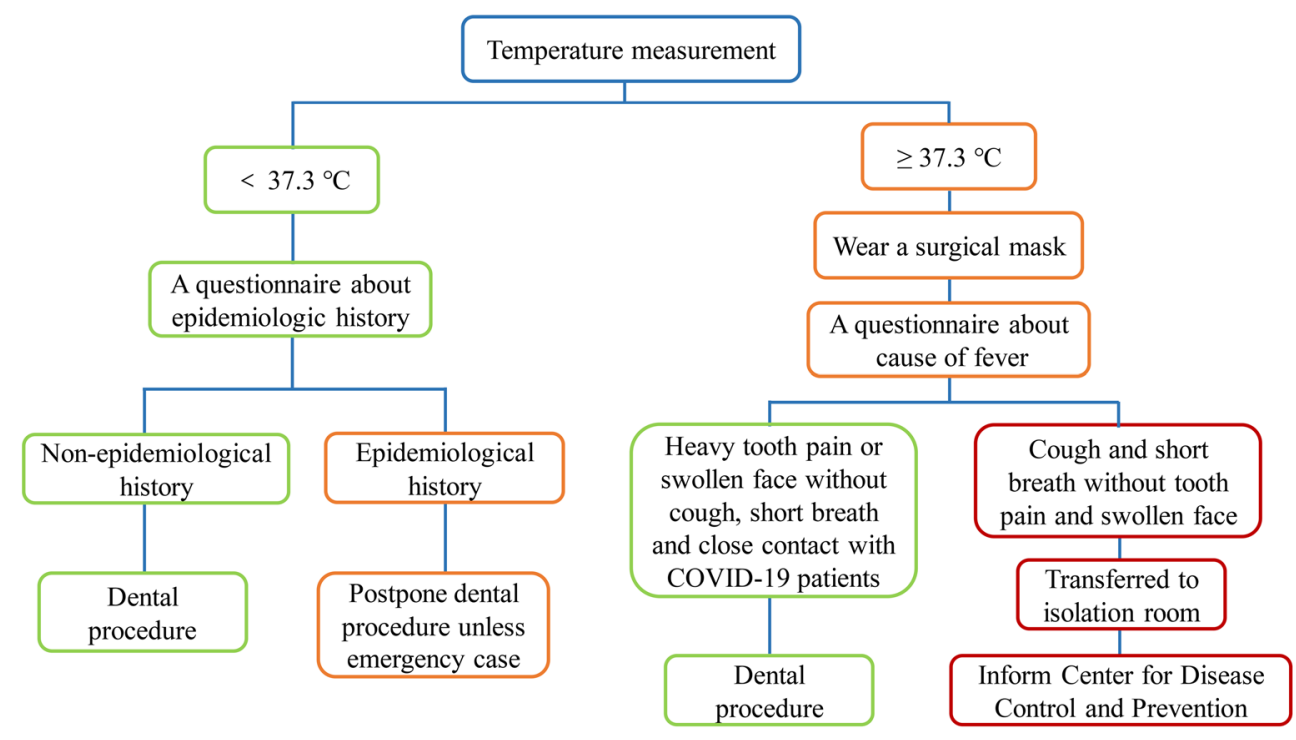

treatment bills were analyzed and aerosol-generating procedures, including an open access to pulp chamber using highspeed handpiece devices, were investigated. Data from the same period were compared year-on-year (2020-on-2019).

\section{SARS-CoV-2 detection and serological testing}

To complete work resumption, hospital staff, including dentists, nurses, students, security guards, and cleaners, at the Affiliated Stomatology Hospital, Zhejiang University School of Medicine (Hangzhou, China) underwent mandatory testing, free of charge, for SARS-CoV-2 detection using nasopharyngeal swabs, real-time fluorescence RT-qPCR, and serological testing (IgG, IgM) during the period of April 28-29, 2020. The detection of SARS-CoV-2 using the RT-qPCR test kits and IgM/IgG antibody rapid tests using the colloidal gold method were performed by Dian Diagnostics Co., Hangzhou, China.

\section{Results}

A total of 49,007 patient visits $(21,138$ males and 27,869 females) were included in this study (Table 2). The number of patient visits per day is listed in Fig. 2. Some patients underwent aerosol-generating procedures. Adults aged 2564 years constituted the largest proportion of patients during the lockdown and reopening periods. Near $50 \%$ of all patients complained of tooth pain due to pulpitis, periapical periodontitis, and periodontal abscess (Table 2). The number of the patient visits per day in the reopening period was significantly increased compared to that in the lockdown period (Fig. 2).

The distribution of patient visits during the lockdown and reopening periods in 2020 and during the corresponding periods in 2019 is listed in Table 3. The number of emergency visits was significantly increased to approximately 16 - and 6.4-fold during the lockdown and reopening periods, respectively, compared with that during corresponding periods in 2019. The total number of patient visits decreased to $6 \%$ (lockdown) and 58\% (reopening), respectively.

A total of 757 staff members underwent nasopharyngeal swab RT-qPCR testing and serological testing. The results showed that for none of the staff members RT-qPCR testing and serological testing (IgG, $\operatorname{IgM}$ ) were positive. Another 17 hospital members, who were on maternity leave or sick leave, were not tested on April 28 and 29, 2020. However, they were tested before they gave birth or returned to work, and none was positive.

\section{Discussions}

The data obtained in this study revealed the significant decline in dental services during the COVID-19 epidemic in the Zhejiang province, China. The COVID-19 epidemic had a negative influence on people's dental care-seeking behavior. The female proportion of dental patients was dramatically increased from $47.2 \%$ during the lockdown period to $57.4 \%$ during the reopening period (Table 2). This might be attributed to the reduced demands of female dental patients, which might be explained by the fact that females showed more apprehension of contracting acute viral respiratory tract infections than males when undergoing dental procedures [20]. Adults at a working age ( 25 to 64 years) constituted the largest proportion of dental patients (Table 2), and comprise the largest proportion of the population in Zhejiang, China. Due to lack of regular dental service, emergency visits during the lockdown period in Hangzhou, China, were dramatically increased compared with the corresponding period in 2019 (Table 3). 
Table 2 Demographic characteristics of patient visits admitted in the hospital during lockdown and reopening periods in 2020

Patient visits in total $(n(\%)) \quad$ Patient visits in lockdown period $(n(\%)) \quad$ Patient visits in reopening period $(n(\%))$

\begin{tabular}{|c|c|c|c|}
\hline \multicolumn{4}{|l|}{ Gender } \\
\hline Male & $21,138(43.1)$ & $1353(52.8)$ & $19,785(42.6)$ \\
\hline Female & $27,869(56.9)$ & $1208(47.2)$ & $26,661(57.4)$ \\
\hline \multicolumn{4}{|l|}{ Age } \\
\hline $0-14$ & $10,569(21.6)$ & $448(17.5)$ & $10,121(21.8)$ \\
\hline $15-24$ & $7501(15.3)$ & $225(8.8)$ & $7276(15.7)$ \\
\hline $25-64$ & $28,438(58.0)$ & $1695(66.2)$ & $26,743(57.6)$ \\
\hline $65+$ & $2499(5.1)$ & $193(7.5)$ & $2306(5.0)$ \\
\hline \multicolumn{4}{|l|}{ Diagnosis } \\
\hline Pulpitis & $4595(9.4)$ & $647(25.2)$ & $3948(8.5)$ \\
\hline Trauma & $230(0.5)$ & $44(1.7)$ & $186(0.4)$ \\
\hline Periapical periodontitis & $5085(10.4)$ & $475(18.5)$ & $4610(9.9)$ \\
\hline Periodontal abscess & $83(0.2)$ & $28(1.1)$ & $55(0.1)$ \\
\hline Others $^{\mathrm{a}}$ & $39,014(79.6)$ & $1367(53.4)$ & $37,647(81.1)$ \\
\hline Total & $49,007(100.0)$ & $2561(100.0)$ & $46,446(100.0)$ \\
\hline
\end{tabular}

Patient visits are presented in number $(n)$ and percentage $(\%)$

${ }^{a}$ Others include cellulitis, chronic periodontitis, oral mucosal diseases, tooth defect, impacted tooth, and patients need for orthodontic treatments

\section{Pre-operative procedures}

To reduce patients' gatherings in the dental hospital, patients were asked to make a dental appointment via the internet or by telephone in advance. Patient triage was performed by a questionnaire about epidemiological history and temperature measurement (Fig. 1). If patients had an increased body temperature or fever (body temperature $\geq 37.3^{\circ} \mathrm{C}$ ), they were immediately given medical surgical masks. Patients were asked whether they had cough and were short of breath or had heavy tooth pain or a swollen oral maxillofacial region. If patients had a fever and/or cough and were short of breath without tooth pain and a swollen face, they were immediately transferred to an isolation room until they were picked up by healthcare staff from the Center for Disease Control and Prevention (CDC) as per the Chinese epidemiological regulation [21]. If patients had heavy tooth pain or a swollen face without any cough and shortness of breath, and were in close contact with COVID-19 patients, they were allowed undergoing a dental procedure [8]. This was also the case for patients with a normal body temperature and who were not in close contact with COVID-19 patients and did not travel to COVID-19 epidemic cities, countries, and territories. If patients experienced severe pain and a swollen face with a cough, which worsens a patients' general health, they were immediately transferred to an isolation room. Next, an emergent procedure, such as open access to a pulp chamber and incision of an abscess, should be carried out. Subsequently, patients waited for pick-up by CDC healthcare staff. COVID19-suspected patients and healthcare workers were tested for SARS-CoV-2 and quarantined until a clean testing report was received. Otherwise, dental procedures were postponed. All

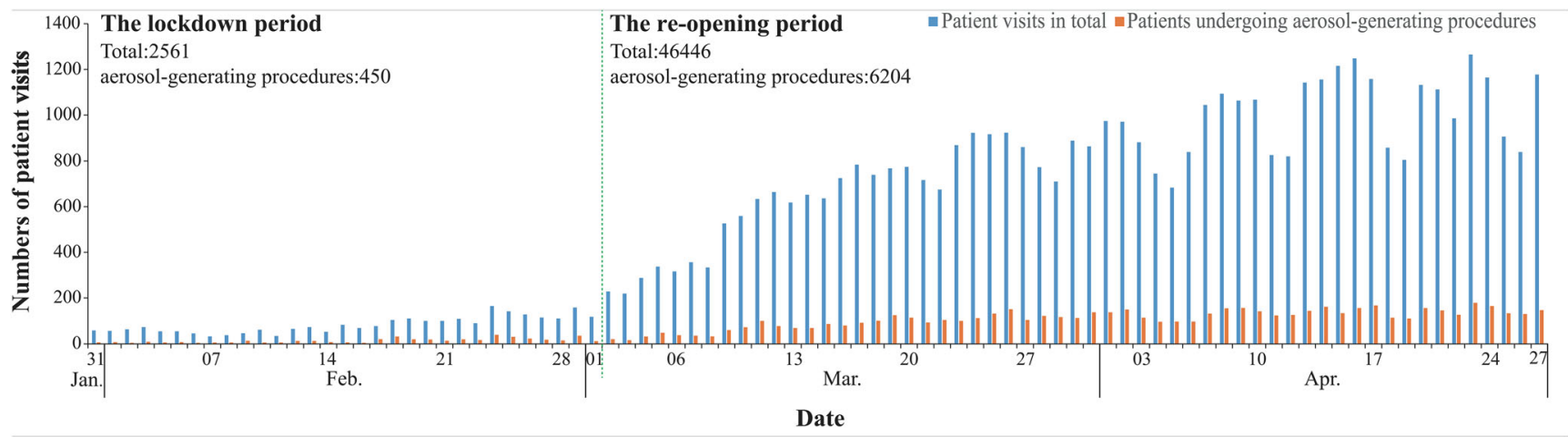

Fig. 2 Total number of patient visits and the number of patients who underwent aerosol-generating procedures in the hospital between January 31,2020 , and April 27, 2020 
Table 3 The distribution of patient visits $(n(\%))$ in lockdown and reopening periods in 2020 and in the corresponding periods in 2019

\begin{tabular}{|c|c|c|c|c|c|c|}
\hline \multirow[t]{2}{*}{ Timeframes } & \multicolumn{3}{|l|}{ Lockdown period } & \multicolumn{3}{|l|}{ Reopening period } \\
\hline & $\begin{array}{l}\text { January } 7 \text { to February } 8 \text {, } \\
2020\end{array}$ & $\begin{array}{l}\text { January } 7 \text { to February } 7, \\
2019\end{array}$ & $\begin{array}{l}\text { Ratio } \\
(2020 / 2019)\end{array}$ & $\begin{array}{l}\text { February } 9 \text { to April 5, } \\
2020\end{array}$ & $\begin{array}{l}\text { February } 8 \text { to April 5, } \\
2019\end{array}$ & $\begin{array}{l}\text { Ratio } \\
(2020 / 2019)\end{array}$ \\
\hline $\begin{array}{l}\text { Emergency } \\
\text { visits }\end{array}$ & $2561(100.0)$ & $160(0.35)$ & 16.01 & $2041(4.39)$ & $318(0.40)$ & 6.42 \\
\hline $\begin{array}{l}\text { Total patient } \\
\text { visits }\end{array}$ & $2561(100.0)$ & $45,517(100.0)$ & 0.06 & $46,446(100.0)$ & $79,525(100.0)$ & 0.58 \\
\hline
\end{tabular}

Timeframes were converted from the solar calendar (January 31 to March 1; March 2 to April 27, 2020) into Chinese lunar calendar (January 7 to February 8; February 9 to April 5, 2020) to obtain the same working days. The year 2020 was a leap year with one extra day (February 29, 2020). Therefore, February 9, 2020, in Chinese lunar calendar was correspondingly antedated to February 8, 2019, for identical working days

patients were instructed to correctly wear face masks and follow a cough etiquette and social distancing [22]. Companions were not allowed entering treatment room unless absolutely necessary [23].

Mouth rinse before dental procedures can reduce a great number of microbes and viral load in the oral cavity [24, 25]. Mouth rinses that efficiently inactivate coronaviruses are recommended, such as povidone-iodine $[3,26]$. However, less effective mouth rinses, such as $0.05-0.2 \%$ benzalkonium chloride and $0.02 \%$ chlorhexidine digluconate, are not recommended [27]. Recently, the virucidal effectiveness of hydrogen peroxide mouth rinses is questionable; therefore, mouth rinses with hydrogen peroxide before dental procedure are no longer recommended [28]. A rubber dam was recommended to be applied and high-volume suction should be implemented whenever a high-speed handpiece device is used, for example, open access to a pulp chamber in case of acute pulpitis. Any aerosol-generating procedures were implemented in an isolated room, or at least in an interval of a dental chair, if an isolation room was not available.

\section{Healthcare staff protective measures}

Dentists and nurses are at high risk of SARS-CoV-2 transmission from their dental patients due to close contact, body fluids, droplets, and aerosol-generating procedures; therefore, standard precaution is of critical importance during dental services, including proper usage of personal protective equipment (PPE) and hand hygiene [29]. This is a routine prerequisite for reducing contact contagion. A suggestive rationalization use of PPE and a dental setting/ device are summarized according to the risk in different situations (Table 1). Standard medical protective masks, for example, N95 masks or equivalent respirators, should be donned during aerosol-generating procedures [30]. Face shields should also be recommended as they could isolate the facial area from aerosols and spatters of body fluids [30]. In this situation, disposable shoe covers are also suggested to be put on. Dentists and nurses should pay high attention to the removal process of PPE and hand hygiene before leaving the treatment room. In addition, hospital administrators should focus on additional measures that prevent dentists and nurses from having to work in a condition that is detrimental to their health and wellbeing as well as to the safety and quality of the care they provide.

Although sensitivity of the RT-qPCR technique might depend on the timing of disease presentation, sampling location, and severity of illness [31], RT-qPCR remains the gold standard test because of the high specificity. The testing method is chemically stable without cross-reactivity with other coronaviruses, and excludes false-positive outcomes based on clinical samples, which pre-tested positive for other respiratory viruses [32]. Despite its high specificity, serological testing cannot exclude COVID-19 due to the limited sensitivity [31]. Therefore, it should only be used as an important test to assist in the diagnosis of COVID-19 [19]. None of the hospital staff was infected with SARS$\mathrm{CoV}-2$. This indicated that the prevention strategy successfully prevented SARS-CoV-2 infections among healthcare workers in the dental hospital. Although the study did not provide the exact data of asymptomatic patients who were treated during the lockdown and reopening periods, the proportion ratio of asymptomatic patients with COVID-19 in the dental hospital was around $0.3 \%$ (Appendix in the Supplementary Information). This is much lower than the prevalence of COVID-19, which was around 2.54\% (1218 cases/47,966 close contact persons) in Zhejiang, China [33]. Thus, asymptomatic carriers with SARS-CoV-2 were estimated to be 49-73.5 during the study period (Appendix in the Supplementary Information). These findings further demonstrated the effectiveness and significance of the applied prevention strategy against the spread of COVID-19 in the dental hospital. The promising data of this prevention strategy could be used as a reference for other countries and territories where patients are suffering from COVID-19 pandemic. 


\section{Limitations in this study}

It is not known whether there were asymptomatic carriers of SARS-CoV-2 among dental patients since not all patients were tested for SARS-CoV-2. The effectiveness and significance of the prevention strategy need to be further verified after treatment of dental patients who contracted SARSCoV-2. Combining RNA detection with antibody testing significantly increased the diagnostic sensitivity of COVID-19 to $99.4 \%$ [34]. However, there is still a risk of small number of false-negative results because of the large number of staff members. Currently, there is no agreed definition of aerosolgenerating procedures [35]. The aerosol-generating procedure documented in this study only involved high-speed handpiece devices and ultrasonic instruments. Other aerosols generated by air-water syringes, prophylaxis, etc. were not sufficiently discussed [35]. Thus, the current methodical approach fails to quantify all aerosol-generating procedures. The information of aerosol-generating procedures was obtained from the datasets of diagnosis and treatment bills, and was based on standard diagnosis and treatment bills. Therefore, the number of aerosol-generating procedures might be more than the numbers presented in Fig. 2. Not exacting data on the adherence to proper PPE use is a limitation of the present study.

\section{Conclusions}

The total number of patient visits was significantly reduced, whereas emergency visits were greatly increased during the COVID-19 pandemic. Healthcare staff in a dental facility should pay much attention not only to patient triage but also to proper use of PPE. The prevention strategy adopted in this study successfully prevented the SARS-CoV-2 spread among healthcare workers in a dental hospital.

Supplementary Information The online version contains supplementary material available at https://doi.org/10.1007/s00784-021-03886-9.

Acknowledgements We thanked Zhongsheng Xu and Wei Chen for data analysis.

\section{Declarations}

Ethics approval All patients included in this study signed written informed consent and agreed that their health-related data would be used for teaching and research purposes. All health-related data were anonymized. Use of these health-related data in the study was strictly abided by the International Ethical Guidelines of the Declaration of Helsinki (World Medical Association, 2008) [36] and National Ethics Censorship of Biomedical Research Involving Human Subject [37]. This study was approved by the Institutional Ethic Board of the Affiliated Stomatology Hospital, Zhejiang University School of Medicine (Hangzhou, China) (No. 2020-16).
Conflict of interest The authors declare no competing interests.

\section{References}

1. Huang C, Wang Y, Li X, Ren L, Zhao J, Hu Y, Zhang L, Fan G, Xu J, Gu X, Cheng Z, Yu T, Xia J, Wei Y, Wu W, Xie X, Yin W, Li H, Liu M, Xiao Y, Gao H, Guo L, Xie J, Wang G, Jiang R, Gao Z, Jin Q, Wang J, Cao B (2020) Clinical features of patients infected with 2019 novel coronavirus in Wuhan, China. Lancet 395:497-506. https://doi.org/10.1016/S0140-6736(20)30183-5

2. Lu C, Liu X, Jia Z (2020) 2019-nCoV transmission through the ocular surface must not be ignored. Lancet 395:e39. https://doi. org/10.1016/S0140-6736(20)30313-5

3. Peng X, Xu X, Li Y, Cheng L, Zhou X, Ren B (2020) Transmission routes of 2019-nCoV and controls in dental practice. Int J Oral Sci 12:9. https://doi.org/10.1038/s41368-020-0075-9

4. Chan JF, Yuan S, Kok KH, To KK, Chu H, Yang J, Xing F, Liu J, Yip CC, Poon RW, Tsoi HW, Lo SK, Chan KH, Poon VK, Chan WM, Ip JD, Cai JP, Cheng VC, Chen H, Hui CK, Yuen KY (2020) A familial cluster of pneumonia associated with the 2019 novel coronavirus indicating person-to-person transmission: a study of a family cluster. Lancet 395:514-523. https://doi.org/10.1016/s01406736(20)30154-9

5. Li Q, Guan X, Wu P, Wang X, Zhou L, Tong Y, Ren R, Leung KSM, Lau EHY, Wong JY, Xing X, Xiang N, Wu Y, Li C, Chen Q, Li D, Liu T, Zhao J, Liu M, Tu W, Chen C, Jin L, Yang R, Wang Q, Zhou S, Wang R, Liu H, Luo Y, Liu Y, Shao G, Li H, Tao Z, Yang Y, Deng Z, Liu B, Ma Z, Zhang Y, Shi G, Lam TTY, Wu J, Gao G, Cowling BJ, Yang B, Leung GM, Feng Z (2020) Early transmission dynamics in Wuhan, China, of novel coronavirus-infected pneumonia. N Engl J Med 382:1199-1207. https://doi.org/10. 1056/NEJMoa2001316

6. Morawska L, Cao J (2020) Airborne transmission of SARS-CoV-2: the world should face the reality. Environ Int 139:105730. https:// doi.org/10.1016/j.envint.2020.105730

7. Amirian ES (2020) Potential fecal transmission of SARS-CoV-2: current evidence and implications for public health. Int $\mathrm{J}$ Infect Dis 95:363-370. https://doi.org/10.1016/j.ijid.2020.04.057

8. Izzetti R, Nisi M, Gabriele M, Graziani F (2020) COVID-19 transmission in dental practice: brief review of preventive measures in Italy. J Dent Res 99:1030-1038. https://doi.org/10.1177/ 0022034520920580

9. Guo H, Zhou Y, Liu X, Tan J (2020) The impact of the COVID-19 epidemic on the utilization of emergency dental services. J Dent Sci 15:564-567. https://doi.org/10.1016/j.jds.2020.02.002

10. Dave M, Seoudi N, Coulthard P (2020) Urgent dental care for patients during the COVID-19 pandemic. Lancet 395:1257. https://doi.org/10.1016/s0140-6736(20)30806-0

11. Wang Y, Liu Y, Liu L, Wang X, Luo N, Ling L (2020) Clinical outcome of 55 asymptomatic cases at the time of hospital admission infected with SARS-coronavirus-2 in Shenzhen, China. J Infect Dis 221:1770-1774. https://doi.org/10.1093/infdis/jiaal19

12. Ahmed MA, Jouhar R, Ahmed N, Adnan S, Aftab M, Zafar MS, Khurshid Z (2020) Fear and practice modifications among dentists to combat novel coronavirus disease (COVID-19) outbreak. Int J Environ Res Public Health 17(8):2821. https://doi.org/10.3390/ ijerph17082821

13. Shacham M, Hamama-Raz Y, Kolerman R, Mijiritsky O, Ben-Ezra M, Mijiritsky E (2020) COVID-19 factors and psychological factors associated with elevated psychological distress among dentists and dental hygienists in Israel. Int J Environ Res Public Health 17(8):2900. https://doi.org/10.3390/ijerph17082900 
14. Coulthard P (2020) Dentistry and coronavirus (COVID-19) - moral decision-making. Br Dent J 228:503-505. https://doi.org/10.1038/ s41415-020-1482-1

15. Zhao J, Zhao S, Ou JX, Zhang J, Lan WD, Guan WY, Wu XW, Yan YQ, Zhao W, Wu JG, Chodosh J, Zhang QW (2020) COVID19: coronavirus vaccine development updates. Frontiers in Immunology 11:602256. https://doi.org/10.3389/fimmu.2020. 602256

16. Ather A, Patel B, Ruparel NB, Diogenes A, Hargreaves KM (2020) Coronavirus disease 19 (COVID-19): implications for clinical dental care. J Endod 46:584-595. https://doi.org/10.1016/j.joen.2020. 03.008

17. Bali RK, Chaudhry K (2020) Maxillofacial surgery and COVID19, the pandemic!! J Maxillofac Oral Surg 19:159-161. https://doi. org/10.1007/s12663-020-01361-8

18. World Health Organization-WHO (2020) Clinical management of severe acute respiratory infection when novel coronavirus (2019$\mathrm{nCoV}$ ) infection is suspected: interim guidance. World Heal Organ. Accessed 30 Apr 2020. Available at: https://www.who.int/ publications-detail/clinical-management-of-severe-acuterespiratory-infection-when-novel-coronavirus-(ncov)-infection-issuspected

19. Cao G, Tang S, Yang D, Shi W, Wang X, Wang H, Li C, Wei J, Ma L (2020) The potential transmission of SARS-Cov-2 from patients with negative RT-PCR swab tests to others: two related clusters of COVID-19 outbreak. Jpn J Infect Dis 73:399-403. https://doi.org/ 10.7883/yoken.JJID.2020.165

20. Ashok N, Rodrigues JC, Azouni K, Darwish S, Abuderman A, Alkaabba AAF, Tarakji B (2016) Knowledge and apprehension of dental patients about MERS-a questionnaire survey. J Clin Diagn Res 10(5):ZC58-ZC62. https://doi.org/10.7860/JCDR/ 2016/17519.7790

21. National Health Commission of the People's Republic of China (2020) Guideline for the diagnosis and treatment of novel coronavirus pneumonia (the 7th edition). Accessed 30 Apr 2020. Available at: http://www.nhc.gov.cn/yzygj/s7653p/202003/ 46 c 9294 a 7 d fe 4 cef 80 d c 7 f 5912 eb $1989 /$ files/ ce3e6945832a438eaae415350a8ce964.pdf

22. National Health Commission of the People's Republic of China (2020) Technical guideline for prevention and control of novel coronavirus infection in medical institutions (the 1st edition). Accessed 30 Apr 2020. Available at: http://www.nhc.gov.cn/xcs/ yqfkdt/202001/b91fdab7c304431eb082d67847d27e14.shtml

23. Yang Y, Soh HY, Cai Z, Peng X, Zhang Y, Guo C (2020) Experience of diagnosing and managing patients in oral maxillofacial surgery during the prevention and control period of the new coronavirus pneumonia. Chin J Dent Res 23:57-62. https://doi.org/ 10.3290/j.cjdr.a44339

24. Marui VC, Souto MLS, Rovai ES, Romito GA, Chambrone L, Pannuti CM (2019) Efficacy of preprocedural mouthrinses in the reduction of microorganisms in aerosol: a systematic review. J Am Dent Assoc 150:1015-1026.e1. https://doi.org/10.1016/j.adaj. 2019.06.024

25. Eggers M, Koburger-Janssen T, Eickmann M, Zorn J (2018) In vitro bactericidal and virucidal efficacy of povidone-iodine gargle/mouthwash against respiratory and oral tract pathogens. Infect Dis Ther 7:249-259. https://doi.org/10.1007/s40121-0180200-7
26. Omidbakhsh N, Sattar SA (2006) Broad-spectrum microbicidal activity, toxicologic assessment, and materials compatibility of a new generation of accelerated hydrogen peroxide-based environmental surface disinfectant. Am J Infect Control 34(5):251-257 Available at:https://pubmed.ncbi.nlm.nih.gov/16765201

27. Carrouel F, Conte MP, Fisher J, Gonçalves LS, Dussart C, Llodra JC, Bourgeois D (2020) COVID-19: A recommendation to examine the effect of mouthrinses with $\beta$-cyclodextrin combined with citrox in preventing infection and progression. J Clin Med 9(4): 1126. https://doi.org/10.3390/jcm9041126

28. Gottsauner MJ, Michaelides I, Schmidt B, Scholz KJ, Buchalla W, Widbiller M, Hitzenbichler F, Ettl T, Reichert TE, Bohr C, Vielsmeier V, Cieplik F (2020) A prospective clinical pilot study on the effects of a hydrogen peroxide mouthrinse on the intraoral viral load of SARS-CoV-2. Clin Oral Investig 24(10):3707-3713. https://doi.org/10.1007/s00784-020-03549-1

29. World Health Organization, WHO Patient Safety (2009) WHO guidelines on hand hygiene in health care: first global patient safety challenge clean care is safer care. Geneva world health organization. Accessed 30 Apr 2020. Available at: https://www.ncbi.nlm. nih.gov/books/NBK144013/

30. Ren Y, Feng C, Rasubala L, Malmstrom H, Eliav E (2020) Risk for dental healthcare professionals during the COVID-19 global pandemic: an evidence-based assessment. J Dent 101:103434. https:// doi.org/10.1016/j.jdent.2020.103434

31. Ong DSY, de Man SJ, Lindeboom FA, Koeleman JGM (2020) Comparison of diagnostic accuracies of rapid serological tests and elisa to molecular diagnostics in patients with suspected coronavirus disease 2019 presenting to the hospital. Clin Microbiol Infect 26:1094.e7-1094.e10. https://doi.org/10.1016/j.cmi.2020.05.028

32. Corman VM, Landt O, Kaiser M, Molenkamp R, Meijer A, Chu DK, Bleicker T, Brünink S, Schneider J, Schmidt ML, Mulders DG, Haagmans BL, van der Veer B, van den Brink S, Wijsman L, Goderski G, Romette J-L, Ellis J, Zambon M, Peiris M, Goossens H, Reusken C, Koopmans MP, Drosten C (2020) Detection of 2019 novel coronavirus (2019-ncov) by real-time rt-pcr. Euro Surveill 25(3):2000045. https://doi.org/10.2807/1560-7917.ES.2020.25.3. 2000045

33. Health Commission of Zhejiang Province (2020) COVID-19 epidemic situation in Zhejiang Province, April 28, 2020. Accessed 16 Feb 2021. Available at: http://wsjkw.zj.gov.cn/art/2020/4/28/art 1202194 42731715.html

34. Cui FY, Z̄hou HS (2020) Diagnostic methods and potential portable biosensors for coronavirus disease 2019. Biosens Bioelectron 165: 112349. https://doi.org/10.1016/j.bios.2020.112349

35. Innes N, Johnson IG, Al-Yaseen W, Harris R, Jones R, Kc S, McGregor S, Robertson M, Wade WG, Gallagher JE (2021) A systematic review of droplet and aerosol generation in dentistry. J Dent 105:103556. https://doi.org/10.1016/j.jdent.2020.103556

36. World Medical Journal (2008) WMA Declaration of Helsinki ethical principles for medical research involving human subjects. World Med J 27:235-237

37. No. 11 Bulletin of National Health Commission of People's Republic of China, 2016, Accessed 13 Jun 2020. Available at: http://www.gov.cn/gongbao/content/2017/content_5227817.htm

Publisher's note Springer Nature remains neutral with regard to jurisdictional claims in published maps and institutional affiliations. 